\title{
Observations on liver regeneration after right hepatic lobectomy
}

\author{
L. H. BLUMGART, K. G. LEACH, AND S. J. KARRAN \\ From the Departments of Surgery and Medical Physics, Welsh National School of Medicine
}

SUMMARY Restoration of liver mass has been studied in five patients after right hepatic lobectomy. The operation effects an approximate $50 \%$ resection of liver substance. Postmortem observations, measurements of the weight of liver resected at operation, and the study of serial radioisotopic liver scans suggest that liver regeneration in man is initiated very soon after partial hepatectomy and is well advanced within 10 days of operation.

The remarkable regenerative capacity of the liver following major hepatic resection is well documented. It has been estimated that function and mass return to normal levels within four to six months of operation (Pack, Islami, Hubbard, and Brasfield, 1962; McDermott, Greenberger, Isselbacher, and Weber, 1963; McDermott, 1970). However, recent reports (Siemsen and Parker, 1967; DeLand and Wagner, 1968; Samuels and Grosfeld, 1970; Taylor and Blumgart, 1971; Blumgart and Vajrabukka, 1971) have suggested that the rate of regeneration of the liver after right hepatic lobectomy may be much more rapid than has been suspected previously.

This communication reports observations made on the rate of liver regeneration in five patients after right hepatic lobectomy. Full clinical details of these cases have been reported (Blumgart and Vajrabukka, 1971). Of the five it was possible to observe the livers of two at necropsy and the remaining three were studied using radioisotopic scans at intervals after operation.

\section{Materials and Methods}

Five patients with extensive injury to the right lobe of the liver were submitted to right hepatic lobectomy. The operative technique employed was essentially that described by Lloyd-Davies and Angell (1957) and by Quattlebaum and Quattlebaum (1958). The patients were aged between 9 and 23 years old and all were healthy before injury with no history of liver disease. One patient died 10 hours and another 10 days after operation but the remaining three survived (Table I). Liver function was assessed in the three surviving patients.

Received for publication 18 August 1971.
The weight of the liver removed at operation was recorded in all cases except one and at necropsy in the two patients who died. These weights are compared with the expected liver weight derived from the body surface area using the equation:

liver weight $(\mathrm{kg})=1.02$ body surface area $\left(\mathrm{m}^{2}\right)$ 0.22 (DeLand and North, 1968).

Surface area was calculated from the height and weight of each patient using the equation:

surface area $\left(\mathrm{cm}^{2}\right)=$ weight $(\mathrm{kg})^{0.425} \times$ height $(\mathrm{cm})^{0.725} \times 71.84$ (Dubois and Dubois, 1916) (Table I).

The rate of liver regeneration in the three patients who survived was assessed by serial liver scanning performed with Technetium $99 \mathrm{~m}$ sulphur colloid prepared by the method of Larson and Nelp (1966), using both a rectilinear scanner (Picker Magnascanner V) and a gamma camera (Nuclear Chicago Pho-gamma III). These scans were carried out from the fourth postoperative day until nine months after operation (Table II).

In order to obtain an assessment of liver size an outline of each scan was made by one of us (K.G.L.) who was unaware of the partial hepatectomy date. The area so outlined was then measured independently by another (S.J.K.). Both anterior and right lateral views were traced and measured. The edge of the liver scan was usually fairly definite but outlining required some personal judgement. It was found that the outlines of the spleen and liver were somewhat more difficult to separate than the images obtained for normal spleen and liver, so that in the anterior views both were included in the outline area. In the case of the rectilinear photoscans technical factors used in performing the scans somewhat influence their size, but there is always a 


\begin{tabular}{|c|c|c|c|c|c|c|c|}
\hline Case & $\begin{array}{l}\text { Sex } \\
\text { and } \\
\text { Age }\end{array}$ & Outcome & Height (cm) & $\begin{array}{l}\text { Body Weight } \\
(k g)\end{array}$ & $\begin{array}{l}\text { Expected Liver } \\
\text { Weight ( } k g \text { from } \\
\text { surface area) }\end{array}$ & $\begin{array}{l}\text { Weight of Liver } \\
\text { Removed at } \\
\text { Operation }(\mathbf{k g})\end{array}$ & $\begin{array}{l}\text { Weight of Liver } \\
\text { Remnant at Necropsy } \\
(\mathrm{kg})\end{array}$ \\
\hline 2 & $\begin{array}{l}\mathbf{M} \\
\mathbf{2 2}\end{array}$ & Survived & 165 & $54 \cdot 1$ & $1 \cdot 4$ & 0.650 & - \\
\hline 3 & $\begin{array}{l}\text { F } \\
9\end{array}$ & Survived & 127 & $25 \cdot 5$ & 0.75 & 0.375 & - \\
\hline 4 & $\begin{array}{l}M \\
13\end{array}$ & Survived & 142 & 31 & 0.92 & 0.449 & - \\
\hline 5 & $\begin{array}{l}\mathbf{M} \\
\mathbf{2 3}\end{array}$ & $\begin{array}{l}\text { Died } 10 \text { hours } \\
\text { after operation }\end{array}$ & Not recorded & Not recorded & $1 \cdot 8^{1}$ & 0.745 & $0 \cdot 745$ \\
\hline
\end{tabular}

Table I Comparison of weights of liver at necropsy, of liver removed at operation, and the expected weight ${ }^{1}$ Upper range of normal for young man $1.8 \mathrm{~kg}$ (Deland and North, 1968). Height and body weight not known.

fixed relationship of $1: 1$ between the detector and the film. There is no fixed relationship between the gamma camera pictures and organ size, but during the period of the scan the magnification, measured using a line phantom, did not vary by more than $\pm 5 \%$.

Both the anterior and right lateral views were measured at intervals after operation. The area of the rectilinear scans was expressed in $\mathrm{sq} \mathrm{cm}$ and that of the gamma camera scans in sq $\mathrm{mm}$. No attempt was made to relate the area of the scan to the weight of the liver.

\section{Results}

THE LIVER WEIGHT AND POSTMORTEM OBSERVATIONS

In the patient who died 10 hours after hepatic lobectomy the liver showed no macroscopic evidence of increase in size and the remnant removed at necropsy (Fig. 1) was the same weight as that removed at operation the day before (case 5, Table I). This observation is particularly interesting since the weight of the liver removed at operation in cases 2 , 3 , and 4 is also approximately half the calculated liver weight (Table I). Thus the operation of right hepatic lobectomy in which the line of resection runs through the liver substance just medial to the gallbladder bed seems to effect a resection of $50 \%$ of the liver mass.

The patient who came to necropsy 10 days after hepatic lobectomy was found to have a large liver. Its consistency and shape was good and it weighed $1.7 \mathrm{~kg}$ (Table I). The height and body weight of this patient were not recorded but he was well above average size. His liver weight would be unlikely to exceed $1.8 \mathrm{~kg}$ (DeLand and North, 1968). It can therefore be reasonably assumed that in this case the liver virtually reached its preoperative weight within 10 days. Liver scanning was not performed in this patient.

\section{LIVER SCANS}

The results of the scan studies in the three patients who survived are shown in Table II. In case 2 gamma camera scans were not available for some months after operation but rectilinear scans were carried out from the fourth day to the ninth month after operation. These scans demonstrate the early

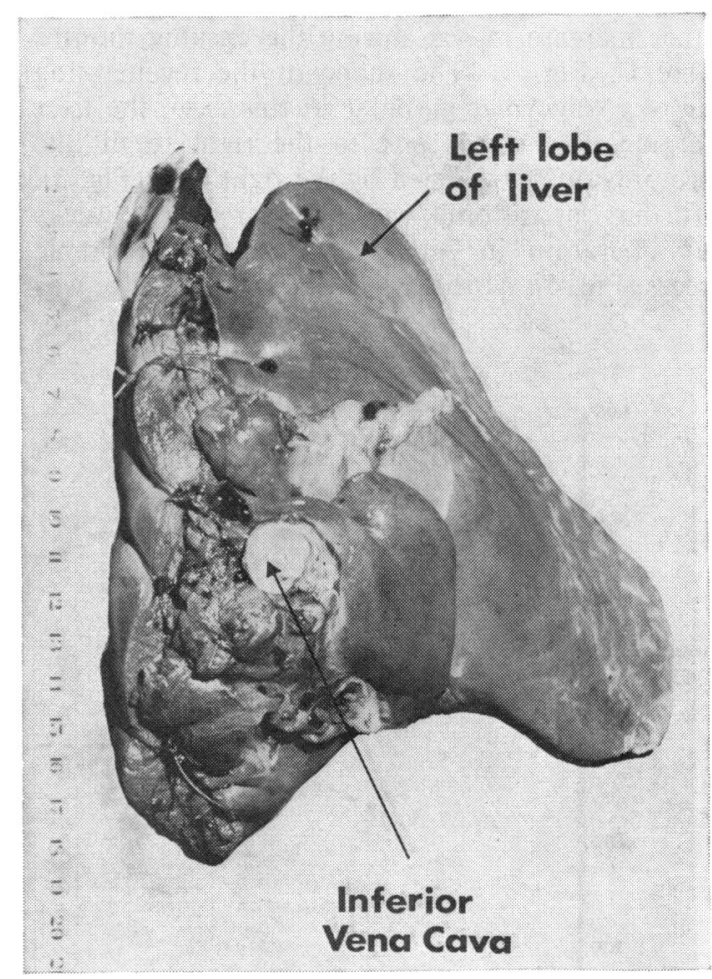

Fig. 1 Inferior surface of the liver removed at necropsy 10 hours after right hepatic lobectomy (case 5). Note that the line of resection, which commenced anteriorly just medial to the gallbladder fossa, has finished posteriorly just to the right of the inferior vena cava. 


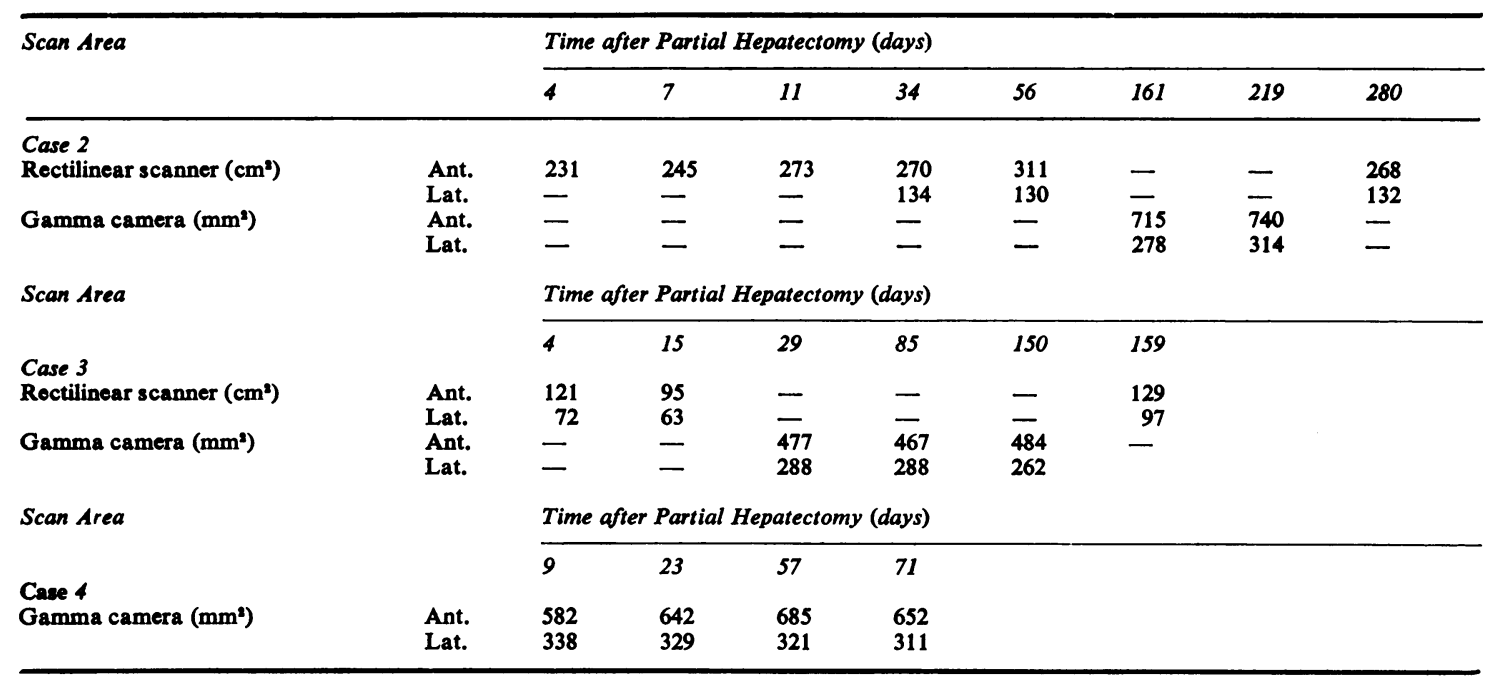

Table II Scan areas measured at intervals after right hepatic lobectomy in three surviving cases

increase in the size of the liver during the first 10 postoperative days. There was, however, little if any further increase in size during the ensuing months (Table II, Fig. 2). The shape of the regenerating liver was somewhat globular in this case, the liver enlarging downwards and to the right to fill the space previously occupied by the right lobe (Fig. 3). A further laparotomy was necessary three weeks after operation in order to drain a subphrenic abscess (Fig. 4). At this operation the liver edge was noted close to the costal margin, from which it was separated by the abscess cavity.

The findings in cases 3 and 4 confirm that there was little increase in the size of the liver as judged by scan area after the first postoperative week (Table II). In case 3 the size of the scan remained remarkably constant after the fourth postoperative day. In this patient the liver remnant appeared not only to enlarge towards the right side of the abdomen but also into the left subdiaphragmatic space, splenec-

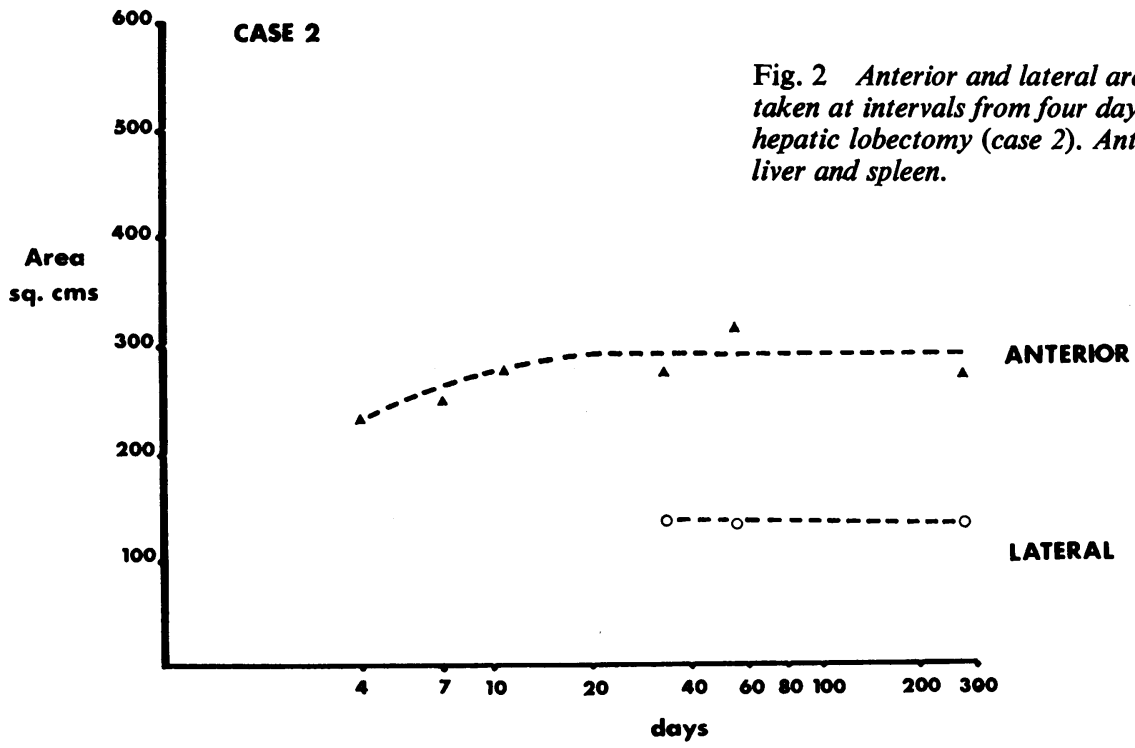




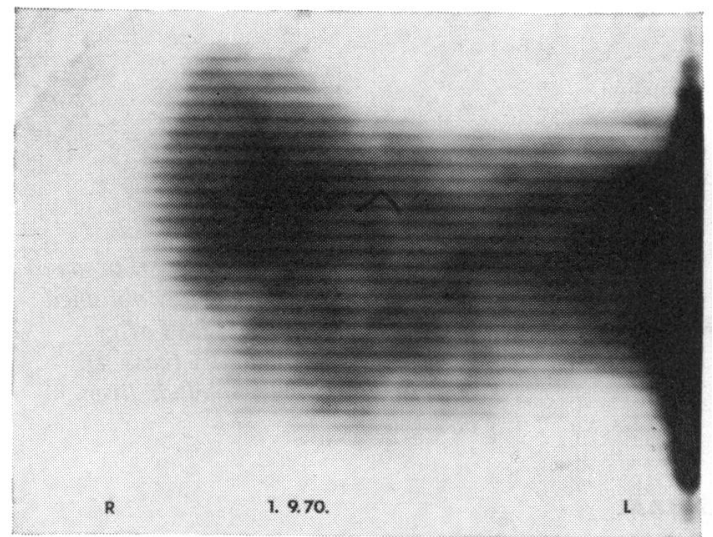

Fig. 3a.

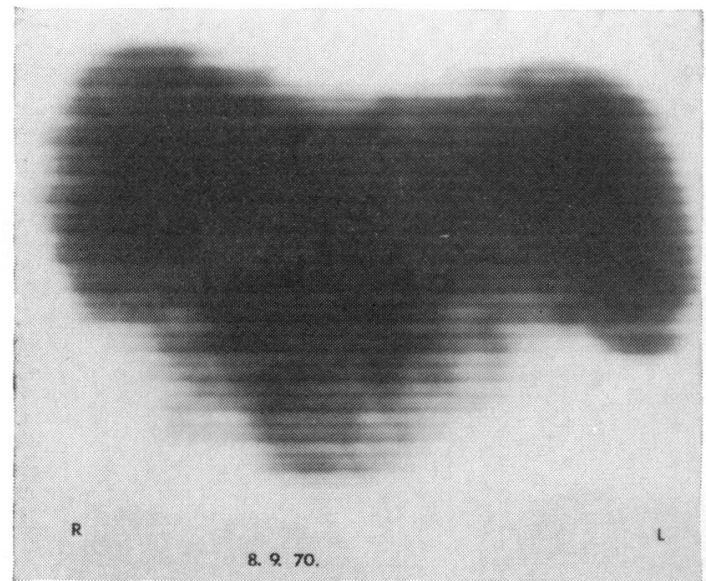

Fig. 3b.

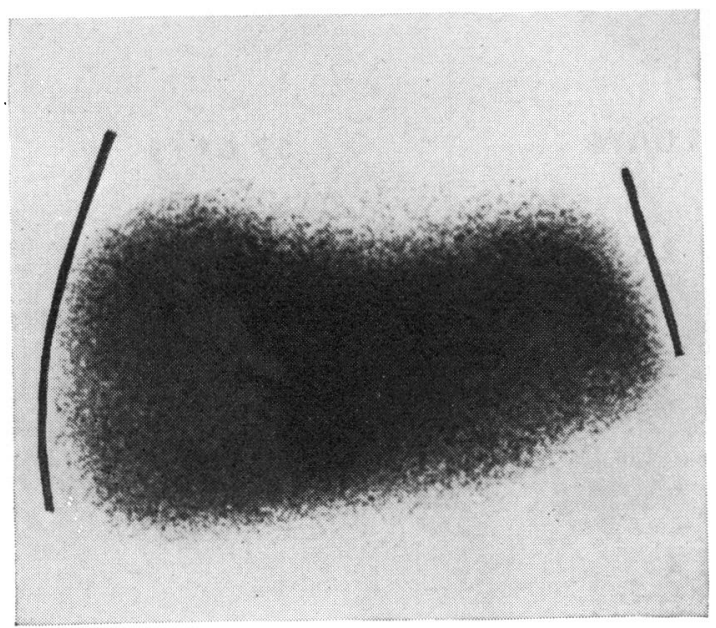

Fig. 3 Rectilinear scans taken (a) four days and (b) 11 days after right hepatic lobectomy (case 2).

Fig. 4 Sinogram to demonstrate right subphrenic abscess cavity 29 days after right hepatic lobectomy (case 2). The regenerating liver was separated from the costal margin by the abscess cavity.

Fig. 5 Anterior gamma camera scan of case 3 one month after right hepatic lobectomy. Splenectomy was carried out in this patient. The liver has enlarged not only towards the right but also into the space previously occupied by the spleen. The black lines are judged to outline the thoracic cage. 


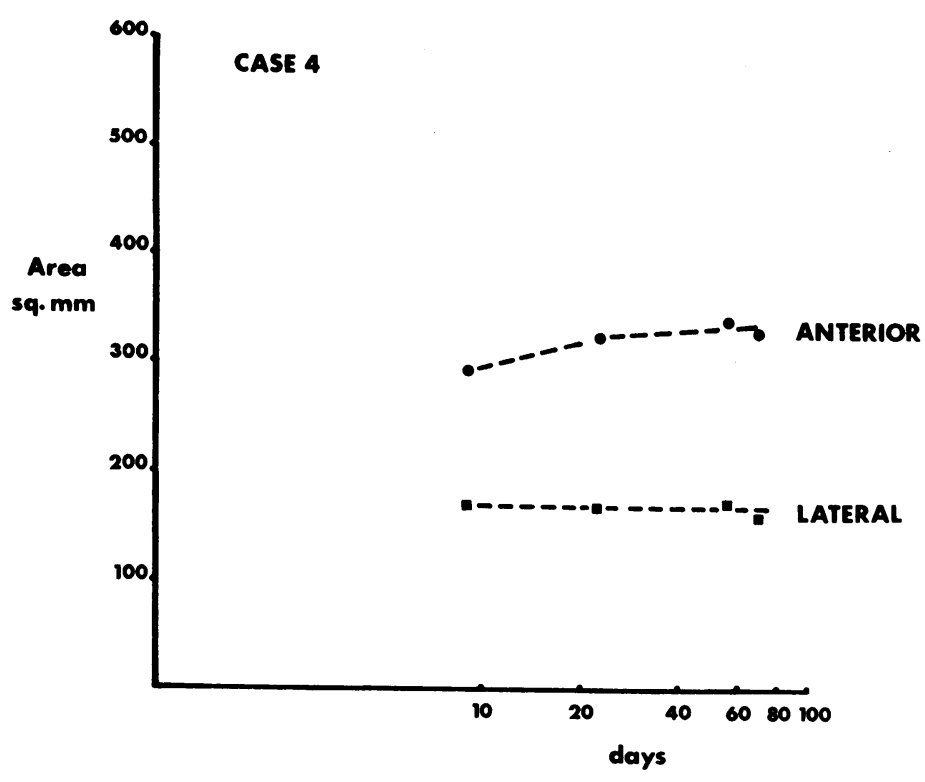

Fig. 6 Anterior and lateral areas of gamma camera liver scans obtained from nine days to 71 days after right hepatic lobectomy (case 4). Anterior scan areas include liver and spleen.

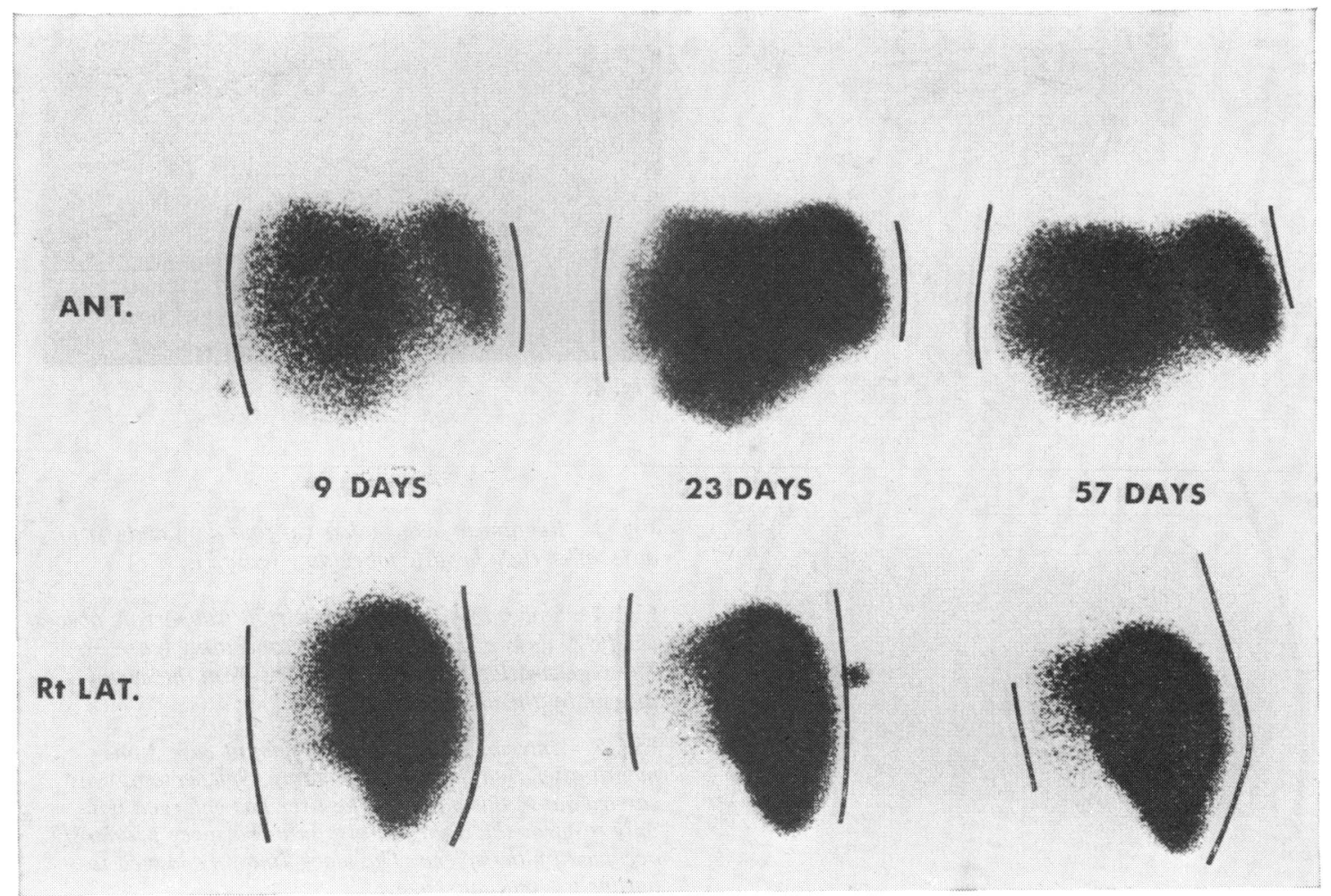

Fig. 7 Anterior and right lateral gamma camera scans (case 4) obtained nine days, 23 days, and 57 days after right hepatic lobectomy. The black lines are judged to outline the thoracic cage. 
tomy having been carried out in addition to right hepatic lobectomy (Fig. 5).

Similarly in case 4 there was only a small increase in the measured area of the liver scan after the ninth postoperative day (Table II, Fig. 6). Representative scans obtained with the gamma camera at intervals after operation are shown in Figure 7.

The results in the three surviving patients demonstrate that the liver attains a good size within the first 10 postoperative days and that there is little increase in the size of the scan thereafter. The direction in which the liver remnant enlarges appears to be in part dependent on pressure factors.

In the patients who survived recovery of liver function was noted between the second and sixth weeks after operation (Blumgart and Vajrabukka, 1971).

\section{Discussion}

The rate of regeneration of the liver in the rat is well documented. Complete replacement of liver mass has been demonstrated within three weeks of partial hepatectomy (Harkness, 1957) and studies in our laboratories suggest that the process may be even more rapid (Karran, Leach, and Blumgart, 1971). This process of regeneration commences very soon after hepatectomy with the peak of mitosis occurring some 24 hours after operation (Weinbren, 1959).

It has, as yet, not been possible to obtain exact measurements of the rate of liver regeneration in man. Such estimates as have been made suggest that once initiated liver regeneration may proceed as rapidly as $\mathbf{5 0} \mathrm{g}$ liver tissue being replaced per day (Pack et al, 1962). Complete restoration of liver mass has been thought to take place within four to six months of hepatectomy (McDermott et al, 1963; McDermott, 1970). However, some authors (Siemsen and Parker, 1967; DeLand and Wagner, 1968) have suggested that the rate of regeneration may be considerably quicker and Samuels and Grosfeld (1970) have reported scans approximating to the size one would expect for a normal liver in young children subjected to extensive hepatic resection 10 days previously. The same suggestion has been made by others (Taylor and Blumgart, 1971; Blumgart and Vajrabukka, 1971).

Our observations suggest that approximately $50 \%$ of the liver is resected at right hepatic lobectomy and support the contention that liver regeneration commences soon after operation and progresses rapidly during the subsequent 10 days. There is little increase in liver size over the following months. The shape of the regenerating liver mass is somewhat dependent on pressure factors, but in general after right hepatic lobectomy the liver regenerates in a globular fashion towards the right side of the subdiaphragmatic space as originally reported by McDermott et al (1963).

Recent reports have demonstrated a correlation between measurements of scan size and the weight of the spleen or liver. It has been shown that the height of the spleen measured from the scan correlates with spleen weight accurately enough for clinical purposes (Sigel, Becker, and Hurley, 1970; Larson, Tuell, Moores, and Nelp, 1970). Others have shown a relationship between the area of scans of liver and spleen and the weight of these organs (Spencer and Banever, 1970; Fischer and Wolf, 1964). Whilst we have simply assessed the size of the liver scan at varying times after hepatectomy and have made no attempt to correlate this with the weight of the liver, it seems reasonable to equate a constant scan area with constant liver weight (Spencer and Banever, 1970).

Although the colloid is only taken up by the reticulo-endothelial system it has been shown that, in the regenerating rat liver, there is no significant difference between the scans of the liver using the colloid and those obtained using ${ }^{75} \mathrm{Se}$ Selenomethionine which is concentrated by the hepatocytes (Karran et al, 1971).

It has been shown experimentally that proliferative activity in the liver is accompanied by depression of normal function. During regeneration it would appear that much of the cellular energy is occupied with division and that proportionately less is available for normal liver function (Weinbren, 1959). In our patients recovery of liver cellular function was noted within two weeks of operation and by the sixth postoperative week liver function was virtually normal (Blumgart and Vajrabukka, 1971). This early recovery of cellular function after massive liver resection has also been noted by others (Parker and Siemsen, 1967) and lends strength to the proposition that restoration of much of the liver mass has taken place by at least the fourth or fifth week after operation.

It is a pleasure to acknowledge the help of Dr. A. S. Bligh of the Department of Diagnostic Radiology and of Mr R. Marshall of the Department of Medical Illustration, both at Cardiff Royal Infirmary.

Blumgart, L. H., and Vajrabukka, T. (1971). Injuries to the liver-an analysis of 20 cases with particular reference to liver resection and regeneration. Brit. med. J. (In press.)

DeLand, F. H., and North, W. A. (1968). Relationship between liver size and body size. Radiology, 91, 1195-1198.

Deland, F. H., and Wagner, H. N., Jr. (1968). Regeneration of the liver after hepatectomy. J. nucl. Med., 9, 587-589.

Dubois, D., and Dubois, E. F. (1916). A height-weight formula to estimate the surface area of man. Proc. Soc. Exp. Biol. (N.Y.), 13, 77-78.
} 
Fischer, J., and Wolf, R. (1964). Quantitative estimation of spleen size by scintigraphy. Germ. med. Mth., 9, 63-68.

Harkness, R. D. (1957). Regeneration of liver. Brit. med. Bull., 13. 87-93.

Karran, S. J., Leach, K. G., and Blumgart, L. H. (1971). Liver scanning in the rat. (In preparation.)

Larson, S. M., and Nelp, W. B. (1966). Radiopharmacology of a simplified Technetium-99m-Colloid preparation for photoscanning. J. nucl. Med., 7, 817-826.

Larson, S. M., Tuell, S. H., Moores, K. D., and Nelp, W. B. (1970). Dimensions of the normal spleen and prediction of spleen weight. J. nucl. Med., 11, 341.

Lloyd-Davies, O. V., and Angell, J. C. (1957).Right hepatic lobectomy. Operative technique, some anatomical points and an account of a case. Brit. J. Surg., 45, 113-117.

McDermott, W. V., Jr., Greenberger, N. J., Isselbacher, K. J., and Weber, A. L. (1963). Major hepatic resection: diagnostic techniques and metabolic problems. Surgery, 54, 56-66.

McDermott, W. V., Jr. (1970). Circulatory changes associated with major hepatic resection. Ann. N.Y. Acad. Sci., 170, 246-250.

Pack, G. T., Islami, A. H., Hubbard, J. C., and Brasfield, R. D.
(1962). Regeneration of human liver after major hepatectomy. Surgery, 52, 617-623.

Parker, J. J., and Siemsen, J. K. (1967). Liver regeneration following hepatectomy evaluated by scintillation scanning. Radiology, 88, 342-344.

Quattlebaum, J. K., and Quattlebaum, J. K., Jr. (1958). Technic of hepatic lobectomy. Ann. Surg., 149, 648-651.

Samuels, L. D., and Grosfeld, J. L. (1970). Serial scans of liver regeneration after hemihepatectomy in children. Surg. Gynec. Obstet., 131, 453-457.

Siemsen, J. K., and Parker, J. J. (1967). Liver regeneration following hepatectomy, evaluated by scintillation scanning. J. nucl. Med., 8, 309.

Sigel, R. M., Becker, D. V., and Hurley, J. R. (1970). Evaluation of spleen size during routine liver imaging with ${ }^{00 m} \mathrm{Tc}$ and the scintillation camera. J. nucl. Med., 11, 689-692.

Spencer, R. P., and Banever, C. (1970). Growth of the human liver: a preliminary scan study. J. nucl. Med., 11, 660-662.

Taylor, I., and Blumgart, L. H. (1971). Right hemi-hepatectomy for extensive liver injury. Brit. J. clin. Pract., 85, 81-84.

Weinbren, K. (1959). Regeneration of the liver. Gastroenterology, 37, 657-668.
Endocrine tumour in kidney affecting small bowel structure, motility, and absorptive function $\mathbf{M . ~} \mathbf{H}$. GLEESON, S. R. BLOOM, J. M. POLAK, K. HENRY, AND R. H. DOWLING

Neural crest origin of the endocrine polypeptide (APUD) cells of the gastrointestinal tract and pancreas A. G. E. PEARSE AND JULIA M. POLAK

Incidence of small-intestinal mucosal abnormalities and of clinical coeliac disease in the relatives of children with coeliac disease D. C. ROBINSON, A. J. WATSON, E. H. WYATT, J. M. MARKS, AND D. F. ROBERTS

Impaired lymphocyte reactivity against tumour cells in patients with coeliac disease B. P. MACLAURIN, W. T. COOKE, AND N. R. LING

Intramural cysts of the ileum C. D. Collins, L. Low, AND A. C. HUNT

Intestinal lymphoma and sprue: A systematic approach WERNER DUTZ, SHAHLA ASVADI, SHAHNAZ SADRI, AND ELFRIEDE KOHOUT
Potassium transport in the human small bowel L. A. TURNBERG

Aspirin and alcohol in gastrointestinal haemorrhage C. D. NEEDHAM, J. KYLE, P. F. JONES, S. J. JOHNSTON, AND D. F. KERRIDGE

Radiographic demonstration of gastric variceal bleeding $K$. J. HOURIGAN

The fate of pentagastrin BRIAN H. STAGG, JOHN M. TEMPERLEY, AND JOHN H. WYLLIE

Portal hypertension in primary biliary cirrhosis M. C. KEW, R. R. VARMA, H. A. DOS SANTOS, P. J. SCHEUER, AND SHEILA SHERLOCK

Progress report Diagnosis of insulinoma VINCENT MARKS

Progress report Anal continence H. L. DUTHIE

The British Society of Gastroenterology

Notes and activities

Copies are still available and may be obtained from the PUBLISHING MANAGER,

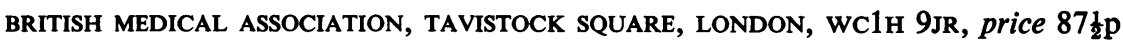

